mised. As heparin has a short half life errors of $20 \%$ or more, which occurred in $12 \%$ and $20 \%$ of observations, may influence the thromboplastin time, depending on their relation to when blood is taken for monitoring, the concentration of heparin used, and the flow rate.

Delay in measurement may result in a fall in the thromboplastin time, ascribed to in vitro release of heparin neutralising activity from platelets. ${ }^{5} \mathrm{We}$ found falls of up to 27 seconds, which could result in unnecessary changes in dose or even a serious underestimate of the thromboplastin time. In view of the factors described fine tuning of the heparin dose may be unrealistic. Control may be improved by following published guidelines, ${ }^{1}$ and by aiming for the midpoint of the therapeutic range to accommodate unavoidable sources of variation. Subcutaneous heparin may be a more reliable alternative to infusion, particularly when only a roller clamp system is available.

AF was in receipt of the Morrison-Davies travelling fellowship. MNL is a clinical trials scholar of the National Cancer Institute of Canada.

1 Fennerty A, Campbell IA, Routledge PA. A regular review: anticoagulants in venous thromboembolism. $\mathrm{Br}$ Med $\mathcal{F}$ 1988;297:1285-8.

2 Fennerty A, Thomas P, Backhouse G, Bentley P, Campbell IA, Routledge PA. Audit of control of heparin treatment. Br Med f 1985;290:27-8.

3 Cross RE, Vance JR. In vivo accuracy of gravity-flow IV infusion systems. $A m \mathcal{f}$ Hosp Pharm 1985;42:328-31.

4 Anonymous. Infusion pumps. Health Devices 1979;8:103-31.

5 Van de Besselaar AMHP, Meeuwisse-Braun J, Jansen-Gruter R, Bertina RM. Monitoring heparin therapy by activated partial thromboplastin time-the effect of pre-analytical conditions. Thromb Haemost 1987;52:226-31.

(Accepted 13 February 1989)

\title{
Immunisation state of children born before term in the Northern region
}

\author{
U Wariyar, S Richmond, P Morrell
}

\begin{abstract}
Princess Mary Maternity Hospital, Newcastle upon Tyne NE2 3BD U Wariyar, MCRP, research registrar in paediatrics
\end{abstract}

\section{Sunderland General Hospital, Sunderland SR4 7TP \\ S Richmond, MRCP, consultant paediatrician}

Middlesbrough General Hospital, Middlesbrough, Cleveland TS5 5AZ

P Morrell, MRCP, consultant paediatrician

Correspondence to: Dr Wariyar.

BrMed J 1989;299: 1013-4
Preterm infants are often followed up by paediatricians trying to audit the activities of neonatal units. Contact with senior paediatricians might be expected to result in higher uptake of immunisations in this group of vulnerable children than in the general population. We carried out a study to assess this.

\section{Patients, methods, and results}

As part of a study of all infants who were born before 32 weeks' gestation in the Northern region ${ }^{1}$ we looked at the immunisation records kept by health visitors on 230 who had survived two years. We obtained data on 212 of the children.

Diphtheria, tetanus, and polio-Altogether 203 children had received the first dose of diphtheria, tetanus, and polio vaccine. By the age of $2,173 \mathrm{had}$ completed a course of three doses.

Pertussis-Only 114 had received the first dose of pertussis vaccine and only 97 had had a full course by the age of 2 . The parents of 68 had been advised to refuse immunisation against pertussis: 33 by paediatricians, 25 by general practitioners, nine by clinical medical officers, and one by a health visitor. The parents of 30 children had decided to refuse immunisation against pertussis despite the absence of any recognised contraindication. The parents of the 97 children who had not received immunisation against pertussis gave various reasons for this. In 25 cases these reasons were in accordance with guidelines recommended in 1983 by the Department of Health and Social Security: nine children had family histories of epilepsy, three had ventriculoperitoneal shunts, nine had had neonatal fits, three had had intraventricular haemorrhages or clinical evidence of cerebral damage, and one had had meningitis. Four children had not been immunised because they had had apnoea of prematurity, two because they had been adopted, and 36 merely because they had been born before term. Three children who had had mild local reactions to the first dose and four who had had similar reactions to the second dose had not been offered subsequent doses.

Measles-Immunisation against measles had been given to 139 children by the age of 2 , and a further 30 were expected to receive it. Reasons given for not immunising the remaining 43 children were: parental wishes (29 children), prematurity (three), history of measles (three), family history of epilepsy (one), ventriculoperitoneal shunt (one), dystrophia myotonica (one), pertussis vaccine not given (one), and neonatal fits (one); no reason was given for three children.

In $75 \%$ of our sample immunisations had been delayed according to the degree of prematurity: $72 \%$ of diphtheria and tetanus and triple immunisations and $65 \%$ of measles immunisations had been delayed. Delay had been advised by paediatricians ( 58 children), general practitioners (41), and health visitors or clinical medical officers (27).

\section{Comment}

Our results compare quite well with the uptake by all children in the region at that time (table) but less well with the uptake by long term survivors of preterm birth in the United States. ${ }^{2}$ Only $25(12 \%)$ of the

Completed immunisations by age 2 in children born before term and all children. Figures are percentages of children

\begin{tabular}{|c|c|c|c|c|c|}
\hline & \multicolumn{2}{|c|}{$\begin{array}{c}\text { Northern region, } \\
1983\end{array}$} & $\begin{array}{c}\text { England } \\
\text { and Wales, } \\
1983^{\star}\end{array}$ & \multicolumn{2}{|c|}{ United States ${ }^{2}$} \\
\hline & $\begin{array}{c}\text { Born } \\
\text { before } 32 \\
\text { weeks' } \\
\text { gestation }\end{array}$ & $\begin{array}{c}\text { All } \\
\text { children }\end{array}$ & $\begin{array}{c}\text { All } \\
\text { children }\end{array}$ & $\begin{array}{c}\text { Born } \\
\text { weighing } \\
<1500 \mathrm{~g}\end{array}$ & $\begin{array}{c}\text { All } \\
\text { children }\end{array}$ \\
\hline Diphtheria & 82 & 85 & 85 & 83 & 97 \\
\hline Tetanus & 82 & 85 & 85 & 83 & 97 \\
\hline Whooping cough & $46 \dagger$ & 63 & 65 & 83 & 91 \\
\hline Polio & 82 & 85 & 85 & 83 & 97 \\
\hline Measles & 66 & 72 & 68 & NA & 96 \\
\hline
\end{tabular}

$\mathrm{NA}=$ Not available

* Source:' statistics research divisions of Department of Health and Social Security, 1987.

$\dagger 49 \%$ In babies without recognised contraindications.

children had valid reasons for avoiding immunisation against pertussis according to the Department of Health and Social Security's guidelines (1983). These reasons were not valid according to the stricter advice of the American Academy of Pediatrics. ${ }^{3}$ Forty three children had not been immunised on apparently misguided advice from health professionals.

Recommendations about the timing of immunisations in children born before term vary greatly among different centres and paediatricians ${ }^{4}$; many neonatal units do not have an agreed policy. ${ }^{2}$ Guidelines published by the Department of Health and Social Security in 1988 should have changed this ${ }^{5}$; they recommend that immunisation should not be postponed because of prematurity.

Uptake of immunisations in children born before term could be improved by neonatal units deciding at discharge whether each child is suitable. Parents 
should be told of the decision and the child's general practitioner and health visitor informed in writing.

We thank the health visitors who collected the data for this study. UW received a grant from the Northern Regional Health Authority.

1 Wairyar U, Richmond S, Hey E. Pregnancy outcome at 24-31 weeks gestationneonatal survivors. Arch Dis Child 1989;64:678-86.
2 Vohr BR, Oh W. Age of diphtheria, tetanus and pertussis immunisations of special care nursery graduates. Pediatrics 1986;77:569-71.

3 American Academy of Pediatrics. Report of the committee on infectious diseases (the red book). 19th ed. Illinois: American Academy of Pediatrics, 1982.

4 Lingam SL, Pateman J, Beaver R, et al. Immunisation of preterm infants. Br Med F 1986;292:1183-4.

5 Department of Health and Social Security. Immunisation against infectious disease. London: HMSO, 1988:4

(Accepted 17 fuly 1989)

\section{Use of cyanoacrylate tissue adhesive for closing facial lacerations in children}

\section{David P Watson}

\section{Guy's Hospital, London SE1 9RT \\ David P Watson, FRCSI, registrar in accident and emergency medicine and plastic surgery}

BrMed f 1989;299:1014
I report a prospective trial of cyanoacrylate (Histoacryl) tissue adhesive in closing facial lacerations in children aged under 14. A new method of applying the glue by means of capillary tubing was also assessed.

\section{Materials, methods, and results}

Any facial laceration requiring suturing was deemed suitable for gluing except $(a)$ lacerations longer than $3 \mathrm{~cm},(b)$ those including eyelids or the mucocutaneous junction of the mouth, $(c)$ those with ragged edges, and (d) deep or haemorrhagic wounds. Glue was applied by means of glass capillary tubing $7.5 \mathrm{~cm}$ long and $1.5 \mathrm{~mm}$ diameter. The tip of the phial containing the glue was cut at its lowest point to accommodate the applicator. The glue moves up the tubing by capillary attraction.

The skin edges were held together and the glue dabbed along the wound as a thin film. The wound was held for 30 seconds or until the glue became opaque, signifying polymerisation. Dressings were not applied unless the child was very young, when a plaster was used. Parents were advised to keep the area dry for 48 hours and then treat as normal.

Fifty children with lacerations were glued and photographed. Forty five patients returned at two weeks for review, 40 at three months, and 21 at six months. At three months cosmetic results were so good
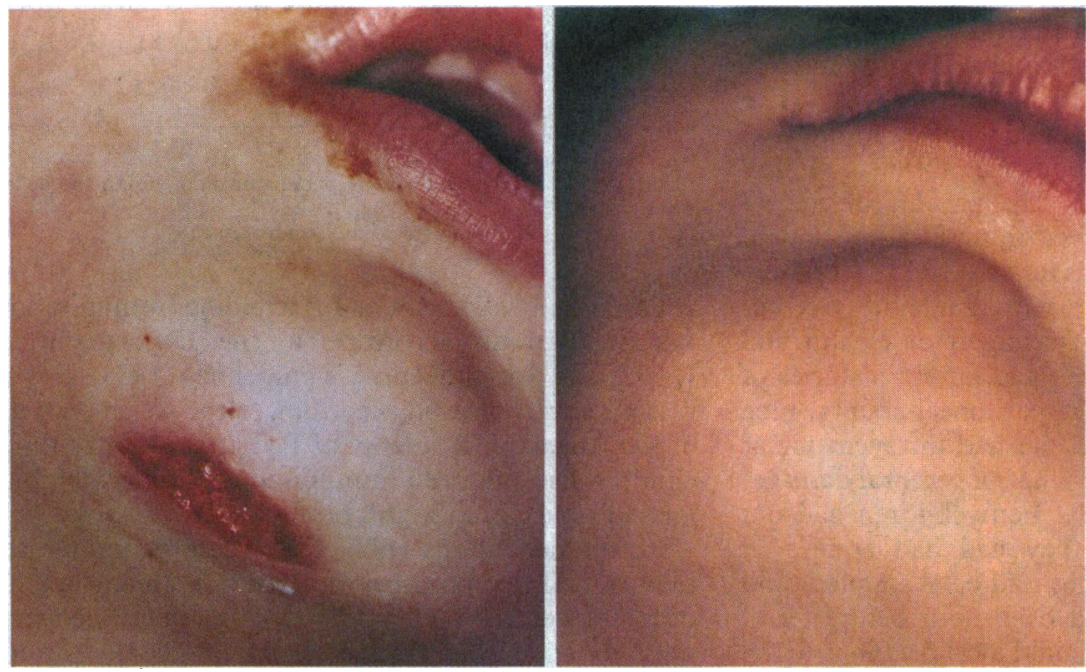

that many patients were not asked to return at six months (figure). Of the $\mathbf{4 0}$ patients reviewed at three months, 35 had wounds that had healed satisfactorily with good cosmetic results, and five had complications (detailed below). There were no problems associated with using the capillary tubing. Staff found it easy to apply and control the amount of glue used, and the time taken for gluing was considerably less than that for suturing (average five minutes as compared with 15). Consequently the procedure was far more acceptable to patients, parents, and medical staff alike.

Complications occurred in five patients. Two wounds became infected, and both were on the forehead. One was cleaned and sutured and healed with a good cosmetic result at three months. A Steristrip was applied to the other, but at three months the scar had spread. In one 7 year old a deep cheek laceration which crossed the nasolabial fold healed well but at three months showed hypertrophic scarring. In another case a 2 year old picked and reopened the wound, and at the parents' request the wound was sutured. Finally, one scar was "unusual." A 10 year old had a laceration on his chin glued. The scar faded but developed pearl white growths along its length. Histologically the scar showed keratin pits consistent with an inclusion body type reaction.

\section{Comment}

Gluing is quick, atraumatic to all concerned, and cost effective,' particularly when capillary tubing is used. Furthermore, the cosmetic results are excellent. Some children experience minor discomfort from the heat of the polymerisation, but this is less painful than injections. The cost per application is $45 \mathrm{p}$ compared with $90 \mathrm{p}$ for a $5 / 0$ nylon suture.

It is undesirable to use the same phial on different patients, even with trimming the tip of the phial. The use of capillary tubing overcomes this problem. Cultures of glue taken at weekly intervals were negative.

The wound is assessed by a casualty officer, and, if suitable, the senior nursing staff in our paediatric accident and emergency department now perform the gluing routinely. The child may be discharged with instructions to return only if there are complications; reattendance is not mandatory. This contrasts with suturing, after which the patient must have the sutures removed.

I am grateful to Dr L Stimmler and Major General N G Kirby for generous advice and to the staff of the paediatric accident and emergency department at Guy's Hospital.

1 Dalui A, Faria M, Pierto A. Non-suture closure of wounds using cyanoacrylate. f Postgrad Med 1986;32:97-100.

(Accepted 26 July 1989) 